\title{
EDITORIAL
}

\section{A propósito del Grupo Bolivariano}

Una de las metas de la Junta Directiva de la FECOLSOG, se encuentra dirigida hacia el fortalecimiento del Grupo Bolivariano.

Vale la pena entonces informar qué es, no sin antes iniciar con un recuento de su origen en los grupos regionales de la FLASOG.

Los anteriores son organizaciones científicas sin fines lucrativos, los cuales agrupan las federaciones o sociedades nacionales de Obstetricia y Ginecología, filiales de la FLASOG, de países con vecindad geográfica, intereses comunes en la especialidad y medios de comunicación apropiados que permitan el intercambio necesario entre ellos.

El Grupo Bolivariano constituido por Bolivia, Colombia, Ecuador, Perú y Venezuela nace en La Paz-Bolivia, en 1985, en Asamblea Ordinaria de la Federación Latinoamericana de Sociedades de Obstetricia y Ginecología y es ratificado en Asamblea Extraordinaria en Caracas en 1986. De esta manera ingresa a completar los Grupos Regionales con el del Cono Sur (Argentina, Chile, Uruguay y Paraguay), el Grupo de México y Centro América y el Grupo del Caribe.

En estas circunstancias se reglamentan sus finalidades, las cuales básicamente se orientaron a fomentar el progreso, el adelanto científico y académico de la especialidad, promoviendo investigación científica e intercambio de experiencias con programas multinacionales sobre temas de interés común.

Se acordó organizar jornadas, reuniones o cursos de actualización en forma rotatoria por lo menos una vez al año y se decidió nombrar un coordinador por cada país, quien sería el Presidente de la Federación, o Sociedad, o su delegado.

En lo que a nuestro país se refiere, al hablar del Grupo Bolivariano es imposible no mencionar a la persona del Dr. Francisco Pardo Vargas, nuestro expresidente, quien ha sido el coordinador no sólo a nivel nacional sino con los demás integrantes del grupo, para asesorar y guiar lo que hasta el momento Colombia ha logrado en la ejecución de investigaciones colaborativas multinacionales sobre embarazo en adolescentes y morbi mortalidad materna por aborto. Los resultados y conclusiones obtenidas se presentaron en el Congreso Latinoamericano de la Especialidad en 1990, con el beneplácito y mención de elogio por parte de la Asamblea Ordinaria.

El Grupo se ha venido reuniendo en un espacio denominado Jornadas Bolivarianas, en el marco del congreso nacional de cada país y también figura en el programa científico de cada evento latinoamericano desde su iniciación.

En el momento actual pretendemos continuar con el liderazgo alcanzado en nuestros países vecinos y presentamos en las últimas jornadas un protocolo de investigación relacionado con un programa de atención institucional al adolescente.

No descuidaremos el cáncer ginecológico ni la morbi mortalidad materna y perinatal y en relación con los últimos dos parámetros desearíamos que nuestros países salieran de la zona catalogada como de alto riesgo para mortalidad materna en Latinoamérica y dejáramos de contribuir con el 10\% de la mortalidad perinatal en el mundo.

Tenemos un compromiso con nosotros mismos en las Jornadas Bolivarianas que organizaremos en Medellín 96, con motivo de nuestro Congreso Nacional y con FLASOG 96, en Asunción-Paraguay, donde se presentarán los resultados de las investigaciones realizadas. 